\title{
Allergen, pathogen, or biotechnological tool? The dematiaceous fungi Alternaria what's for it and what's on it?
}

\author{
Waill A. Elkhateeb ${ }^{1 *}$, Abdu Galib AL Kolaibe ${ }^{2}$, Azza Elkhateeb ${ }^{3}$, Ghoson M. Daba ${ }^{1}$ \\ ${ }^{1}$ Chemistry of Natural and Microbial Products, Department, Pharmaceutical Industries Division, National Research Centre, Dokki, Giza, \\ 12622, Egypt. \\ ${ }^{2}$ Microbiology Department, Faculty of science, Taiz University, Taiz, Yemen. \\ ${ }^{3}$ Agriculture engineering, Agri-economy department, Assiut University.
}

*Corresponding Author: Waill A. Elkhateeb, Chemistry of Natural and Microbial Products Department, Pharmaceutical Industries Division, National Research Centre, Dokki, Giza, 12622, Egypt.

Received date: May 20, 2021; Accepted date: June 01, 2021; Published date: June 08, 2021

Citation: Waill A. Elkhateeb, Abdu G. AL Kolaibe, Elkhateeb A., Ghoson M. Daba (2021) Allergen, pathogen, or biotechnological tool? The dematiaceous fungi Alternaria what's for it and what's on it J, Pharmaceutics and Pharmacology Research. 4(3); DOI: $10.31579 / 2693-7247 / 037$

Copyright: @ $\odot$ 2021, Waill A. Elkhateeb, This is an open access article distributed under the Creative Commons Attribution License, which permits unrestricted use, distribution, and reproduction in any medium, provided the original work is properly cited.

\begin{abstract}
Fungi are rich sources of biologically active natural compounds, which are used in the manufacturing of wide range of clinically important drugs. Alternaria is a fungal genus that belongs to family Pleosporaceae, and has been known as a promising secondary metabolites producer. However the same fungus showed harmful pathogenicity against different plants causing crops economical losses, and is a common allergen in humans, growing indoors and causing hay fever or hypersensitivity reactions. Alternaria is a multicultural fungal genus widely distributing in soil and organic matter. It includes saprophytic, endophytic and pathogenic species. This review aims to briefly summarize the structurally different metabolites produced by Alternaria fungi, as well as their occurrences, biological activities and functions.
\end{abstract}

Keywords: alternaria; biological activities; phytotoxins; endophytic fungi; secondary metabolites

\section{Introduction}

Fungi generally and endophytic ones specifically represent future factories and potent biotechnological tools for production of bioactive natural substances, which could extend healthy life of humanity [1]. Fungi play important role in human life such as in agriculture, food industry, medicine, textiles, bioremediation, natural cycling, as bio-fertilizer and in many other ways. Fungi are ubiquitous on earth and represent essential components of many ecosystems where they are involved in many vital processes [2]. Fungi are promising sources for a wide variety of vital metabolites such as alkaloids, flavonoids, phenols, steroids and terpenoids [3-5]. Fungi capacity to synthesize variety of new bioactive metabolites forced researchers to explore these avenues [6]. Fungi are promising sources for such compounds due to their ability to produce assortment of secondary metabolites that could be, if truly investigated, the solution for currently serious problems. Alternaria is one of the pioneer fungi in this field with proven potent ability as promising biotechnological tool to produce industrially, and biologically diverse metabolites [7, 8]. Fungi are well known biotechnological tools that have various applications in the fields of industry. Thanks to their ability to produce set of prestigious enzymes that is eco-friendly and can replace harmful chemicals used in those industries $[9,10]$.

\section{Alternaria sp. description and ecology}

The genus Alternaria comprises a group of fungi in the family Pleosporaceae (Pleosporales, Dothideomycetes, Ascomycota). The genus Alternaria was established in 1817 with Alternaria alternata as a type isolate. Alternaria belongs to the family Dematiaceae and commonly exists as a saprophyte deriving energy through cellulolytic activity [11]. Generally, Alternaria species are inhabitants of soil or decaying (plant based) organic matter. However, some members of this genus are opportunistic pathogens and cause diseases in economically important plants such as ornamentals, vegetables like broccoli, cauliflower, tomatoes citrus, apples, and oil crops. Alternaria fungi, belonging to the Dematiaceae of the Hyphomycetes in the fungi Imperfecti, have a widespread distribution in nature $[11,12]$. Almost any kind of substrate can support these saprophytic species: from flour to leather, from bottled water to textiles. It can grow on food, clothes, materials, goods and paper. As a facultative pathogen it can be found in a variety of cultures, crops and manufactured products [13].

Alternaria genus is currently divided into 26 sections. Alternaria section contains most of the small-spored Alternaria species with concatenated conidia, including important plant, human and postharvest pathogens. Alternaria have been mostly described based on morphology and / or host-specificity, yet molecular variation between them is minimal. Conidiophores of majority of the species of Alternaria produce asexual spores (conidia) measuring between 160-200 $\mu \mathrm{m}$ long. Under in vitroconditions, sporulation occurs at a temperature range of $8-24{ }^{\circ} \mathrm{C}$, 
where mature spores occur after 14-24h. Optimum temperatures are between 16 and $24^{\circ} \mathrm{C}$ where sporulation time ranges from 12 to $14 \mathrm{~h}$ [14]. Moisture in the presence of rain, dew or high humidity are essential for infection and a minimum of $9-18 \mathrm{~h}$ are required for majority of the species $[11,14]$. Continuous moisture of $24 \mathrm{~h}$ or longer practically guarantees infection [15]. Relative humidity of $91.5 \%$ (at $20^{\circ} \mathrm{C}$ ) or higher will result in the production of large numbers of mature spores in $24 \mathrm{~h} \mathrm{[16].}$
Alternaria is a common fungal genus that causes pre- and postharvest damage to agricultural products, including cereal grains, fruits, and vegetables. In addition to spoiling a wide variety of foods. Several Alternaria species are able to produce secondary metabolites considered as both phytotoxins, which play an important role in the pathogenesis of plants, and mycotoxins [17-19]. At least 268 metabolites from Alternaria fungi have been reported in the past few decades. They mainly include nitrogen-containing metabolites, steroids, terpenoids, pyranones, quinones, and phenolics [20-22].
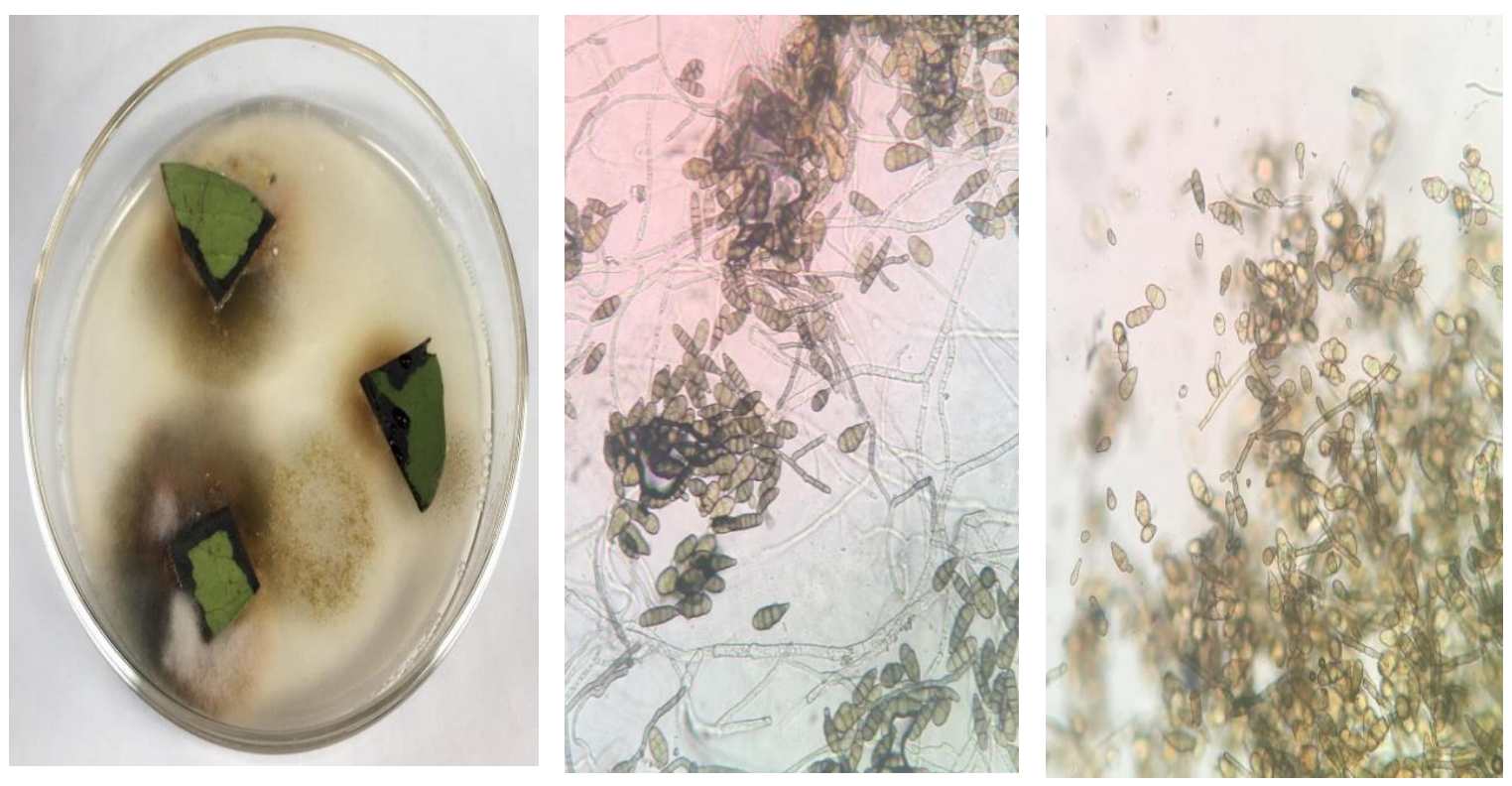

Figure 1. Alternaria sp. with different shapes and septate conidia. On Potato Dextrose Agar, isolated and identified by Dr. Waill Elkhateeb (Photographs was taken by Dr. Waill A. Elkhateeb, Locality: National Research Center of Egypt).

\section{Alternaria sp. secondary metabolites and their biological activities}

Fungi are known to produce a vast array of secondary metabolites that are gaining importance for their biotechnological applications. Microbial secondary metabolites have contributed immensely in the development of a variety of medicines, namely antibiotics, metabolic inhibitors, immunomodulatory agents, antioxidants and anticancer agents [23]. Endophytism in the past decade has further opened avenues of exploration and exploitation of new chemical entities produced during the plantmicrobe interaction for pharmaceutical as well as agricultural applications [23]. Alternaria is a genus belonging to ascomycete and generally comprise of members which cause agricultural spoilage, involved in decay and decomposition and some exist as opportunistic human pathogens. The genus is a prolific producer of secondary metabolites, which are finding applications in the agrochemical as well as pharmaceutical industry [23]. More than 300 metabolites of fungi of the genera Alternaria have been reported in the last few decades; some of them display phytotoxic, antibiotic, antifungal, and antiprotozoal activity $[24,25]$.

Members of the genus Alternaria are known to produce a wide range of phytotoxic secondary metabolites which affect a large number of plants on which the fungus is found [26]. These phytotoxins include alternariol, alternariol monomethyl ether (AME), altenuene, altenuic acid, tenuazonic acid (TA), tentoxin, alternaric acid, AKtoxin and AAL-toxin and posses a broad range of biological and metabolic effects [27, 28]. The metabolites produced by Alternaria exhibit a wide variety of biological activities ranging from phytotoxic, cytotoxic, and antimicrobial activities. Owing to possess such diverse properties, the metabolites of Alternaria have drawn the attention of many chemists, pharmacologists, and plant pathologists to consider them as tools in research programs as well as in application studies $[29,30]$. Alternaria alternata is the most common species and one of the most frequently occurring species of genus Alternaria which is of particular interest because it produces a number of harmful secondary metabolites. Some of the secondary metabolites produced by Alternaria alternata include alternariol, alternariol monomethyl ether, altenuene, tentoxin, tenuazonic acid and many more [17, 18, 31, 32].

\section{Biological Activities and Functions}

Alternaria metabolites have varied chemical properties. Some of them act as phytotoxins to plants or as mycotoxins to humans and animals. They have been examined to have a variety of biological activities and functions, which mainly include the effects on plants, cytotoxic and antimicrobial activities [11, 12].

\section{Effect on plants}

Plant pathogenic Alternaria species can affect cereals, vegetables and fruit crops in the field and during storage. Alternaria fungi contamination is responsible for some of the world's most devastating plant diseases, causing serious reduction of crop yields and considerable economic losses. The metabolites from plant pathogenic fungi are usually toxic to plants and are called phytotoxins. They were further divided into hostspecific and host non-specific toxins. The host-specific toxins (HSTs) are toxic only to host plants of the fungus that produces the toxin [33]. Another definite ion seems to be more acceptable that the host-specific toxins are toxic to plants that host the pathogen, but have lower Phytotoxicity on non-host plants $[34,35]$. Most HSTs are considered to 
be pathogenicity factors, which the fungi producing them require to invade tissue and induce disease [36] All isolates of the pathogen that produce an HST are pathogenic to the specific host.

Interactions between Alternaria species and cruciferous plants were studied in detail by the Pedras group [35]. Nectrophic phytopathogens such as A. alternata and A. brassicae are known to synthesize phytotoxins that damage plant tissues and facilitate colonization, while in response to pathogen attack crucifers biosynthesize phytoanticipins and phytoalexins. Phytoalexins are secondary metabolites produced de novo by plants in response to diverse forms of stress including microbial infection, UV irradiation, and heavy metal salts, whereas phytoanticipins are constitutive defenses whose concentrations can increase upon stress [37]. To the detriment of cruciferous plants, the phytopathogens can overcome phytoanticipins and phytoalexins by producing detoxifying enzymes. For example, the phytoalexin brassinin was detoxified into 3indolylmethanamine and $N$ "-acetyl-3-indolylmethanamine by the pathogen A. brassicae [38]. Very interestingly, cruciferous plants (Brasicca napus and Sinapis alba) can convert host-specific toxins destruxin B and homodestruxin B into less phytotoxic hydrodestruxin B and hydroxyhomodestruxin B, respectively $[39,40]$.

\section{Cytotoxic Activity}

Some Alternaria metabolites have been screened to show cytotoxic activity. They were thought as the potential sources for possible cancer chemo preventive agents. Porritoxin was examined to have anti-tumorpromoting activity [41]. Three amides, AI-77-B, AI-77-F and Sg17-1-4, from a marine fungus $A$. tenuis $\mathrm{Sg} 17-1$ exhibited cytotoxic activity. Al77-B exhibited the cytotoxic activity on human malignant A375-S2 and human cervical cancer [41].

Of Alternaria dibenzopyranones, alternariol was the most active metabolite to have cytotoxic activity on L5178Y mouse lymphoma cells $[42,43]$, as well as to have inhibitory activity on protein kinase and xanthine oxidase [44]. Further investigation showed that alternariol has been identified as a topoisomerase I and II poison which might contribute to the impairment of DNA integrity in human colon carcinoma cells [45]. It induced cell death by activation of the mitochondrial pathway of apoptosis in human colon carcinoma cells. Alternariol and its 9-methyl ether induced cytochrome P450 1A1 and apoptosis in murine heptatoma cells dependent on the aryl hydrocarbon receptor [46]. Dehydroaltenusin, isolated from A. tenuis, was found to be a specific inhibitor of eukaryotic DNA polymerase $\alpha$ to show its strong cytotoxic activity on tumor cells $[47,48]$. Some screened Alternaria anthraquinones displayed cytotoxic activity. Demethylmacrosporin was cytotoxic to Hela and KB cells with IC50 values of $7.3 \mu \mathrm{g} / \mathrm{mL}$ and $8.6 \mu \mathrm{g} / \mathrm{mL}$, respectively [49]. Altersolanol $\mathrm{C}$ was also screened to show cytotoxic activity on a few tumor cells [50]. A few bianthraquinones including alterporriols $\mathrm{A} / \mathrm{B}, \mathrm{C}, \mathrm{D} / \mathrm{E}, \mathrm{F}, \mathrm{K}, \mathrm{L}$, and $\mathrm{P}$ showed strong cytotoxic activity on a few tumor cells [40]. Alterporriol $\mathrm{L}$, a bianthraquinone derivative isolated from a marine fungus Alternaria sp. ZJ9-6B, inhibited the growth and proliferation of the MDA-MB-435 breast cancer cells through destroying the mitochondria [51]. Some Alternaria phenolic metabolites also have cytotoxic activity. Alterlactone from Alternaria sp. was toxic on L5178Y mouse lymphoma cells. Alternethanoxins A and B from A. sonchi displayed growth inhibitory activity on six cancer cell lines [41]. Both 6-(3',3'-dimethylallyloxy)-4methoxy-5-methylphthalide and 5-(3',3'-dimethylallyloxy)-7-methoxy-6methylphthalide were proved to have anti-tumor promoting activity [42]. 5-(3',3'-dimethylallyloxy)-7-methoxy-6-methylphthalide had the cytotoxicity on Hela cells and KB cells with IC50 values as $36.0 \mu \mathrm{g} / \mathrm{mL}$ and $14.0 \mu \mathrm{g} / \mathrm{mL}$, respectively. Porriolide had the cytotoxicity on KB cells with IC50 value as $59.0 \mu \mathrm{g} / \mathrm{mL}$ [41]. Depudecin, an eleven-carbon linear polyketide from Alternaria brassicicola, is an inhibitor of histone deacetylase (HDAC) to show its potential in cancer therapy [43].

\section{Antimicrobial Activity}

Three diketopiperazine dipeptides namely cyclo-[L-Leu-trans-4hydroxy-L-Pro-], cyclo-(LPhe-trans-4-hydroxy-L-Pro-), and cyclo-(LAla-trans-4-hydroxy-L-Pro) extracted from broth culture of the grapevine endophyte Alternaria alternata showed effectiveness by inhibiting sporulation of the pathogen Plasmopara viticola at concentrations of $10-3,10-4,10-5$ and $10-6 \mathrm{~mol} / \mathrm{L}$. This indicated that endophytic fungus A. alternata can be used as biocontrol agent to control fungal disease in grapevine cultivation [52]. Cyclo-(Phe-Ser-) from Alternaria sp. FL25 showed antifungal activity on Fusarium graminearum, $F$. oxysporum, $F$. cucumernum, F. oxysporum. Phytophthora capsici, Colletotrichum gloesporioides with MICs from 6.25 to $25.00 \mu \mathrm{g} / \mathrm{mL}$ [53]. Tenuazonic acid was found to be an active compound in A. alternata against Mycobacterium tuberculosis $\mathrm{H} 37 \mathrm{Rv}$ with MIC value of $250 \mu \mathrm{g} / \mathrm{mL}$. This compound was thought as a promising ant tubercular principle [54]. Other nitrogen-containing metabolites with antimicrobial activity included altersetin, pyrophen, tenuazonic acid and brassicicolin A [38, 55].

Chatterjee et al., [22], reported that Alternaria alternata AE1 exhibited excellent antimicrobial activity especially against both Gram positive and Gram negative bacteria and also showed cidal mode of action. The organism was able to produce a number of antimicrobial compounds in the extracellular broth. The extract of AE1 has exerted adverse effect on central carbohydrate metabolism of pathogenic bacteria. Besides, the EA extract of AE1 exhibited very strong free radical scavenging activity [22].

Helvolic acid from Alternaria sp. FL25, an endophytic fungus in Ficus carica, showed the strong antifungal activity on all tested phytopathogenic fungi (Alternaria alternata, A. brassicae, Botrytis cinerea, Colletotrichum gloesporioides, Fusarium graminearum, $F$. oxysporum, F. oxysporum, F. oxysporum, Phytophthora capsici, Valsa mali) with MICs of 1.56-12.50 $\mu \mathrm{g} / \mathrm{mL}$ [56]. Herbarin A and altechromone A from A. brassicicola ML-P08 exhibited antimicrobial activity on Trichophyton rubrum, Candida albicans, Apergillus niger, Bacillus subtilis, Pseudomonas fluorescens with MICs ranged from 1.8 to 62.5 $\mu \mathrm{g} / \mathrm{mL}$ [57]. Rubrofusarin B from A. alternata showed antifungal activity on Candida albicans [58]. Some anthraquinone metabolites, e.g., macrosporin, hydroxybostrycin, altersolanol A, altersolanol B, altersolanol C, altersolanol $\mathrm{G}$, and alterporriol $\mathrm{C}$ from A. solani and Alternaria sp. showed antibacterial activity on Bacillus subtilis, Escherichia coli, Micrococcus luteus, Pseudomonas aeruginosa, Staphylococcus albus, Staphylococcus aureus, Vibrio parahemolyticus [36]. Two perylenequnones alterperylenol and dihydroalterperylenol from Alternaria sp. had antifungal activity on Valsa ceratosperma. Altenusin and porric acid D from Alternaria sp. showed inhibitory activity against Staphylococcus aureus with MICs of $100 \mu \mathrm{g} / \mathrm{mL}$ and 25 $\mu \mathrm{g} / \mathrm{mL}$, respectively. (4S)- $\alpha, \beta$-Dehydrocurvularin from Alternaria sp. showed inhibitory activity on appressorium formation of Magnaporthe oryzae, and antibacterial activity on Proteus vulgaris and Salmonella typhimurium with MICs as $25 \mu \mathrm{g} / \mathrm{mL}$ [33].

Ghosh et al., [19], reported that Endophytic fungi Alternaria sp. RL4 isolated from Rauvolfia serpentina showed very good antibacterial activities against Gram-positive pathogenic bacterial strains. It can produce at least two different antibacterial compounds with cidal mode of action. In addition, it also showed antioxidant and anticancerous properties. Therefore, Alternaria sp. RL4 could be a very good source of bioactive compounds or in development of new drugs [19].

\section{Other Bioactivities}

Usama et al., [17], reported that Alternaria alternata showing a high level inhibition of HCV protease (IC50 $14.0 \mu \mathrm{g} / \mathrm{mL}$ ) was selected for further investigation on its secondary metabolites. The fungus was identified by its morphology and 18S rDNA. Bioassay guided fractionation of the EtOAc extract of Alternaria alternata culture broth revealed 5 
metabolites: alternariol9methyl ether 3Osulphate, alternariol9methyl ether, alternariol, maculosin and maculosin5. These secondary metabolites act as phytotoxins which are either host specific or nonspecific. In addition, some compounds have antibacterial, anti-viral, cytotoxic or insecticidal effects [18]. Alternariol and alternariol - 9methyl ether were isolated from the ethyl acetate extract of Alternaria alternata PGL-3. The ethyl acetate extracts of Alternaria alternata PGL3 , showed the most potent inhibition of $\mathrm{HCV} \mathrm{NS3/4A} \mathrm{protease} \mathrm{with} \mathrm{IC50}$ 17.0 [59].

From many previous work indicate that some species of micromycetes belonging to the genus Alternaria are able to produce metabolites with insecticidal activity. Thus, fungi of the genus Alternaria, similar to many soil endophytic and phytopathogenic micromycetes, were able to produce phytotoxins, antibiotics, and insecticidal metabolites [60-62].

\section{Conclusion}

Secondary metabolites from the endophytic fungi will be a cheap source for medical, agriculture and other industries. It is sure that the research on endophytic fungi will lead to isolate more novel compounds. This review demonstrate the chemistry and bioactivities of secondary metabolites from the fungal genus Alternaria. A comprehensive investigation of secondary metabolites produced by Alternaria sp. must be carried out for a better understanding of the chemical interactions between Alternaria sp. and its host plants. Many previous research reported that, several metabolites including brassicicolin A, diterpenoides, polyketides, siderophores, alternariol, alternariol methyl ester, tentoxin, tenuazonic acid, altertoxin I, altertoxin II and other were produced by different Alternaria species. Secondary metabolic pathways of Alternaria sp. are strongly dependent on culture conditions, specifically nitrogen sources, ferric ion and temperature. The potential of fungi of the genus Alternaria as producers of biological active compounds remains very high. Secondary metabolites isolated from endophytic genus Alternaria using different culture method like common culture. These compounds have a variety of unique structures, the difference in structure leads to various biological activities of these compounds. Some of these metabolites display significant antimicrobial effects, cytotoxic activities, antioxidant activities and other biological activities, which indicate that they have potential to be agents to treat some diseases.

\section{References}

1. Elkhateeb WA, Daba GM. (2021) The endophytic fungi pestalotiopsis what's for it and what's on it?. Journal of Pharmaceutics and Pharmacology Research, 4(1): 1-5.

2. Elkhateeb WA, Daba GM. (2019) Epicoccum Species as Potent Factories for the Production of Compounds of Industrial, Medical, and Biological Control Applications. Biomed J Sci \& Tech Res, 14(3): 1-5.

3. Calvo AM, Wilson RA, Bok JW, Keller NP. (2020) Relationship between secondary metabolism and fungal development. Microbiology and molecular biology reviews, 66(3): 447-459.

4. Joel EL, Bhimba BV. (2013) Evaluation of secondary metabolites from mangrove associated fungi Meyerozyma guilliermondii. Alexandria J. Med. 49: 189-194.

5. Nisa H, Kamili AN, Nawchoo IA, Shafi S, Shameem N, Bandh SA. (2015) Fungal endophytes as prolific source of phytochemicals and other bioactive natural products: a review. Microb. Pathog. 82: 50-59.

6. Elkhateeb WA, Daba GM. (2020) The Exceptional Endophytic Fungi, Emericella (Berk.) and Phoma (Sacc.) Genera. International Journal of Research in Pharmacy and Biosciences, 7(1):1-6.
7. Elkhateeb WA, Elnahas MO, Daba GM. (2021) Bioactive metabolites of Cunninghamella, Biodiversity to Biotechnology. Journal of Pharmaceutics and Pharmacology Research, 4(3): $1-5$.

8. Elkhateeb WA, Kolaibe AG, Daba GM. (2021). Cochliobolus, Drechslera, Bipolaris, Curvularia different nomenclature for one potent fungus. Journal of Pharmaceutics and Pharmacology Research, 4(1): 1-6.

9. Park M. (2016) Metabolites from the plant pathogen Alternaria brassicicola: in vitro and in planta production and biosynthesis of brassicicolin A (Doctoral dissertation, University of Saskatchewan Saskatoon).

10. Elkhateeb WA, Daba GM. (2019) Myrothecium as promising model for biotechnological applications, potentials and challenges. J. Sci. Res, 16: 12126-12131.

11. Elkhateeb WA. (2005) Some mycological, phytopathological and physiological studies on mycobiota of selected newly reclaimed soils in Assiut Governorate, Egypt (M. Sc. Thesis, Faculty of Science, Assuit University, Egypt. 2005; p 238.

12. Lou J, Fu L, Peng Y, Zhou L. (2013) Metabolites from Alternaria fungi and their bioactivities. Molecules, 18(5): 5891-5935.

13. Thomma BP. (2003) Alternaria spp. From general saprophyte to specific parasite. Mol. Plant Pathol. 4: 225-236.

14. Moubasher AH. (1993) Soil fungi in Qatar and other Arab countries. The Centre for Scientific and Applied Research, University of Qatar.

15. Elkhateeb WA, Daba GM. (2018) Where to Find? A Report for Some Terrestrial Fungal Isolates, and Selected Applications Using Fungal Secondary Metabolites. Biomed Journal Science \&Technology Research 4(4): 1-4.

16. Elkhateeb WA, Zohri AA, Mazen M, Hashem M, Daba GM. (2016) Investigation of diversity of endophytic, phylloplane and phyllosphere mycobiota isolated from different cultivated plants in new reclaimed soil, Upper Egypt with potential biological applications, Inter J MediPharm Res, 2(1): 23-31.

17. Usama Hawas, Samy El-Desouky, Lamia Abou El-Kassem and W. Elkhateeb (2015) Alternariol Derivatives from Alternaria alternata, an Endophytic Fungus Residing in Red Sea Soft Coral, Inhibit HCV NS3/4A Protease. Applied Biochemistry and Microbiology, 51(5): 579-584.

18. Usama W. Hawas, Eman F. Ahmed, Ali Halwany, Ahmed Atif, Waill Ahmed Elkhateeb and Lamia T. Abou El-Kassem (2016) Bioactive metabolites from the Egyptian red sea fungi with potential anti-hcv protease effect. Chemistry of Natural Compounds, 52(1): 104-110.

19. Ghosh R, Ssoma P, Mandal N. (2018) Biological activities of Alternaria sp. rl4-a potent endophytic fungus associated with Rauwolfia serpentine 1. benth. Asian J Pharm Clin res, 11(11), 178-182.

20. Wang Y, Yang MH, Wang XB, Li TX, Kong LY. (2014) Bioactive metabolites from the endophytic fungus Alternaria alternata. Fitoterapia, 99: 153-158.

21. Elgorban AM, Bahkali AH, Al Farraj DA, Abdel-Wahab MA. (2019) Natural products of Alternaria sp., an endophytic fungus isolated from Salvadora persica from Saudi Arabia. Saudi journal of biological sciences, 26(5): 1068-1077.

22. Chatterjee S, Ghosh R, Mandal NC. (2019) Production of bioactive compounds with bactericidal and antioxidant potential by endophytic fungus Alternaria alternata AE1 isolated from Azadirachta indica A. Juss Plos one, 14(4): $\mathrm{e} 0214744$.

23. Saxena S. (2021) Biologically Active Secondary Metabolites from Endophytic Alternaria Species. Endophytes, 1-20. 
24. Orfali RS, Ebrahim W, El-Shafae AM. (2017) Secondary metabolites from Alternaria sp., a fungal endophyte isolated from the seeds of Ziziphus jujuba. Chemistry of natural compounds, 53(6): 1031-1034.

25. Palanichamy P, Krishnamoorthy G, Kannan S, Marudhamuthu M. (2018) Bioactive potential of secondary metabolites derived from medicinal plant endophytes. Egyptian Journal of Basic and Applied Sciences, 5(4): 303-312.

26. Woudenberg JH, Groenewald JZ, Binder M, Crous P. (2013) Alternaria redefined. Studies in mycology, 75: 171-212.

27. Bruce V, Stack M, Mislivec P (1984) Incidence of toxic Alternaria species in small grains from the USA. Journal of food science, 49(6): 1626-1627.

28. Zheng R, Li S, Zhang X, Zhao C. (2021) Biological Activities of Some New Secondary Metabolites Isolated from Endophytic Fungi: A Review Study. International Journal of Molecular Sciences, 22(2): 959.

29. Brase S, Encinas A, Keck J, Nising CF. (2009) Chemistry and biology of mycotoxins and related fungal metabolites. Chemical reviews, 109(9): 3903-3990.

30. Meena M, Prasad V, Upadhyay RS. (2017) Evaluation of Alternaria alternata isolates for metabolite production isolated from different sites of Varanasi. India. J. Agric. Res, 2: 000124.

31. Lou J, Yu R, Wang X, Mao Z, Fu L, Liu Y, Zhou L. (2016) Alternariol 9-methyl ether from the endophytic fungus Alternaria sp. Samif01 and its bioactivities. Brazilian journal of microbiology, 47(1): 96-101.

32. Dalinova AA, Salimova DR, Berestetskiy AO. (2020) Fungi of the genera Alternaria as producers of biological active compounds and mycoherbicides. Applied Biochemistry and Microbiology, 56: 256-272.

33. Tsuge T, Harimoto Y, Akimitsu K, Ohtani K, Kodama M, et al. (2013) Host-selective toxins produced by the plant pathogenic fungus Alternaria alternata. FEMS Microbiol. Rev. 37: 44-66.

34. Graniti A. (1991) Phytotoxins and their involvement in plant diseases. Experientia 47: 751-755.

35. Pedras MS, Biesenthal CJ, Zaharia IL. (2000) Comparison of the phytotoxic activity of the phytotoxin destruxin B and four natural analogs. Plant Sci., 156: 185-192.

36. Howlett BJ. (2006) Secondary metabolite toxins and nutrition of plant pathogenic fungi. Curr. Opin. Plant Biol. 9: 371-375.

37. Pedras MS, Yaya EE, Glawischnig E. (2011) The phytoalexins from cultivated and wild crucifers: chemistry and biology. Nat. Prod. Rep., 28: 1381-1405.

38. Pedras MS, Chumala P, Jin W, Islam M, Hauck D. (2009) The phytopathogenic fungus Alternaria brassicicola: Phytotoxin production and phytoalexin elicitation. Phytochemistry 70: 394-402.

39. Pedras MS, Montaut S, Zaharia I, Gai Y, Ward DE. (2003) Transformation of the host-selective toxin destruxin B by wild crucifers: probing a detoxification pathway. Phytochemistry 64: 957-963.

40. Horiuchi M, Tokuda H, Ohnishi K, Yamashita M, Nishino H, Maoka T. (2006) Porritoxins, metabolites of Alternaria porri, as anti-tumor-promoting active compounds. Nat. Prod. Res. 20: 161-166.

41. Aly A, Edrada-Ebel R, Indriani I, Wray V, Muller W, et al. (2008) Cytotoxic metabolites from the fungal endophyte Alternaria sp. and their subsequent detection in its host plant Polygonum senegalense. J. Nat. Prod., 71, 972-980.

42. Gu W. (2009) Bioactive metabolites from Alternaria brassicicola ML-P08, an endophytic fungus residing in Malus halliana. World J. Microbiol. Biotechnol. 25: 1677-1683.
43. Bury M, Punzo B, Berestetskiy A, Lallemand B, Dubois J, et al. (2011) Evaluation of the anticancer activities of two fungal polycyclic ethanones, alternethanoxins $\mathrm{A}$ and $\mathrm{B}$, and two of their derivatives. Int. J. Oncol. 38: 227-232.

44. Ostry V. (2008) Alternaria mycotoxins: an overview of chemical characterization, producers, toxicity, analysis and occurrence in foodstuffs. World Mycotoxin J. 1: 175-188.

45. Bensassi F, Gallerne C, Sharaf El Dein O, Hajlaoui M, Bacha H, Lemaire C. (2012) Cell death induced by the Alternaria mycotoxin alternariol. Toxicol. In Vitro, 26: 915-923.

46. Schreck I, Deigendesch U, Burkhardt B, Marko D, Weiss C. (2012) The Alternaria mycotoxins alternariol and alternariol methyl ether induce cytochrome P450 1A1 and apoptosis in murine hepatoma cells dependent on the aryl hydrocarbon receptor. Arch. Toxicol. 86: 625-632.

47. Phuwapraisirisan P, Rangsan J, Siripong P, Tip-pyang S. (2009) New antitumour fungal metabolites from Alternaria porri. Nat. Prod. Res. 23: 1063-1071.

48. Mizushina Y, Maeda N, Kuriyama I, Yoshida H. (2011) Dehydroalternusin is a specific inhibitor of mammalian DNA polymerase $\alpha$. Expert Opin. Inv. Drug. 2011, 20, 1523-1534.

49. Huang C-H, Pan J-H, Chen B, Yu M, Huang H-B, et al. (2011) Three bianthraquinone derivatives from the mangrove endophytic fungus Alternaria sp. ZJ9-6B from the South China Sea. Mar. Drugs, 9: 832-843.

50. Huang C, Jin H, Song B, Zhu X, Zhao H, et al. (2012) The cytotoxicity and anticancer mechanisms of alterporriol $\mathrm{L}$, a marine bianthraquinone, against MCF-7 human breast cancer cells. Appl. Microbiol. Biotechnol. 93: 777-785.

51. Zheng C-J, Shao C-L, Guo Z-Y, Chen J-F, Deng D-S, et al. (2012) Bioactive hydroanthraquinones and anthraquinone dimers from a soft coral-derived Alternaria sp. fungus. J. Nat. Prod. 75: 189-197.

52. Musetti R, Polizzotto R, Vecchione A, Borselli S, Zulini Let al. (2007) Antifungal activity of diketopiperazines extracted from Alternaria alternata against Plasmopara viticola: an ultrastructural study. Micron 38: 643-650.

53. Feng C, Ma Y. (2010) Isolation and anti-phytopathogenic activity of secondary metabolites from Alternaria sp. FL25, an endophytic fungus in Ficus carica. Chin. J. Appl. Environ. Biol. 16: 76-78.

54. Sonaimuthu V, Parihar S, Thakur JP, Luqman S, Saikia D, e al. (2010) Tenuazonic acid: A promising antitubercular principle from Alternaria alternata. Microbiol. Res. 2: 63-65.

55. Okamura N, Haraguchi H, Hashimoto K, Yagi A. (1993) Altersolanol-related antimicrobial compounds from a strain of Alternaria solani. Phytochemistry 1993, 34, 1005-1009.

56. Xu X, Zhao S, Wei J, Fang N, Yin L, Sun J. (2012) Porric acid $\mathrm{D}$ from marine-derived fungus Alternaria sp. isolated from Bohai Sea. Chem. Nat. Compd. 47: 893-895.

57. Jeon Y-T, Ryu K-H, Kang M-K, Park S-H, Yun H, QT P, Kim S-U. (2010) Alternariol monomethyl ether and $\alpha, \beta-$ dehydrocurvularin from endophytic fungi Alternaria spp. Inhibit appressorium formation of Magnaporthe grisea. J. Korean Soc. Appl. Biol. Chem. 53: 39-42.

58. Shaaban M, Shaaban KA, Abdel-Aziz MS. (2012) Seven naphtho- $\gamma$-pyrones from the marinederived fungus Alternaria alternata: Structure elucidation and biological properties. Org. Med. Chem. Lett. 2: 6.

59. Abou El-Kassem L, Hawas UW, El-Souda S, Ahmed EF, ElKhateeb W, Fayad W. (2019) Anti-HCV protease potential of endophytic fungi and cytotoxic activity. Biocatalysis and Agricultural Biotechnology, 19: 101170. 
60. Berestetskiy AO, Gannibal FB, Minkovich EV, Osterman IA, Salimova DR, Sergiev PV, Sokornova SV. (2018) Spectrum of biological activity of the Alternaria fungi isolated from the phyllosphere of herbaceous plants. Microbiology, 87(6): 806816.

61. Lakshmi AI, Madhusudhan T, Kumar PD, Padmavathy J, saravanan D, Kumar PC. (2011) Histone deacetylase inhibitors in cancer therapy: an update. Int. J. Pharm. Sci. Rev. Res. 10: $38-44$.

62. Muria-Gonzalez MJ, Chooi YH, Breen S, Solomon PS. (2015) The past, present and future of secondary metabolite research in the Dothideomycetes. Molecular plant pathology, 16(1): 92107.
This work is licensed under Creative Commons Attribution 4.0 License

\section{To Submit Your Article Click Here: Submit Manuscript}

DOI: $10.31579 / 2693-7247 / 037$
Ready to submit your research? Choose Auctores and benefit from:

* fast, convenient online submission

* rigorous peer review by experienced research in your field

* rapid publication on acceptance

* authors retain copyrights

* unique DOI for all articles

* immediate, unrestricted online access

At Auctores, research is always in progress.

Learn more www.auctoresonline.org/journals/pharmaceutics-andpharmacology-research 